\title{
Retrieval of water vapor using SSM/I and its relation with the onset of monsoon
}

\author{
R. P. Singh ${ }^{1,2}$, S. Dey ${ }^{1}$, A. K. Sahoo ${ }^{2}$, and M. Kafatos ${ }^{2}$ \\ ${ }^{1}$ Department of Civil Engineering, Indian Institute of Technology Kanpur-208016, India \\ ${ }^{2}$ School of Computational Sciences, George Mason University, Fairfax, Virginia 22030, USA
}

Received: 23 February 2004 - Revised: 3 June 2004 - Accepted: 21 June 2004 - Published: 7 September 2004

\begin{abstract}
The seasonal variations and interannual variability of total precipitable water (TPW) deduced from the Special Sensor Microwave Imager (SSM/I) satellite over oceanic regions of the Indian sub-continent during the years between 1988 to 1998 show characteristic behavior. The weekly patterns of TPW are found to be closely related to the dynamics of the climatic conditions and the onset date of monsoon. The present results show that the satellite monitoring of TPW may prove as a good and reliable indicator in forecasting Indian monsoon.
\end{abstract}

Key words. Meteorology and atmosphereic dynamics (climatology; tropical meteorology) - Oceanography; general (ocean prediction)

\section{Introduction}

Water vapor plays a major role in the dynamics of atmospheric circulation, as well as in radiation exchange with the atmosphere (Ross and Elliott, 1996). The knowledge of total water vapor has paramount importance to the understanding of monsoon behavior, which, in turn, helps in weather forecasting. Numerous scientists have successfully deduced the surface temperature over land and ocean (McFarland et al., 1990), TPW over ocean surface (Alishouse et al., 1990), rainfall and clouds over oceanic region (Ferraro et al., 1996; Prabhakar et al., 1982; Stephens, 1990; Weng and Grody, 1994) and atmospheric water vapor over ocean (Schluessel and Emery, 1990) using passive microwave remote sensing data. Singh et al. (2000) have analyzed the monthly and seasonal TPW over the Arabian Sea and the Bay of Bengal, and have found a close relationship with monsoon. Simon and Joshi (1994) have studied the changes in TPW from NOAA/TOVS over various regions of the Indian Ocean, the Bay of Bengal and the Arabian Sea. Recently, Simon et al. (2001) have found a sharp increase in water vapor three

Correspondence to: R. P. Singh

(rsingh3@gmu.edu) weeks before the onset of monsoon, based on Multi-scanner Microwave Radiometer (MSMR) data for a limited period of April-June 2000.

In the present paper, weekly and monthly averaged TPW over the Indian oceanic region $\left(0-15^{\circ} \mathrm{N}, 60-80^{\circ} \mathrm{E}\right)$ for the years between 1988 to 1998 have been analyzed during May and June to examine the behavior of TPW over the Arabian Sea and the Indian Ocean around the monsoon onset period. The monthly averaged latitudinal variations of TPW have been compared with the sea surface temperature (SST) during 1994 to 1998. The onset dates of monsoon during 19881998 show a characteristic behavior, showing maxima TPW near the southern Indian coast $\left(10-15^{\circ} \mathrm{N}\right)$ where the monsoon hits first. Efforts have been made further to find a close relation to the daily TPW with the onset dates of monsoon. Due to poor temporal resolution of SSM/I data, the present study is based on six days of averaged TPW, which show a maxima peak of TPW about 8-9 days prior to the onset day of monsoon.

\section{SSM/I Data}

SSM/I is flown on the Defense Meteorological Satellite Program (DMSP) Block 5D-2F8 spacecraft in a circular Sunsynchronous near-polar orbit at an altitude of $833 \mathrm{~km}$ with an inclination of $98.8^{\circ}$ and an orbit period of $102.0 \mathrm{~min}$. The orbit produces 14.1-full orbit rotation per day, and has a 06:13 a.m. local ascending node equatorial crossing. The $\mathrm{SSM} / \mathrm{I}$ is a seven-channel, four-frequency, linearly polarized, passive microwave radiometric system. It receives vertically and horizontally linearly polarized radiations at 19.35 , 37.0 and $85.5 \mathrm{GHz}$ and only vertically polarized radiation at $22.235 \mathrm{GHz}$. The sensor samples every $12.5 \mathrm{~km}$ alongtrack at $85.5 \mathrm{GHz}$ and every $25.0 \mathrm{~km}$ in all other frequencies (Hollinger, 1991). SSM/I covers the whole globe in two days with some gaps in data. The NOAA/NASA Pathfinder Programme EASE-Grid brightness temperature data have been obtained from the National Snow and Ice Data Center, 

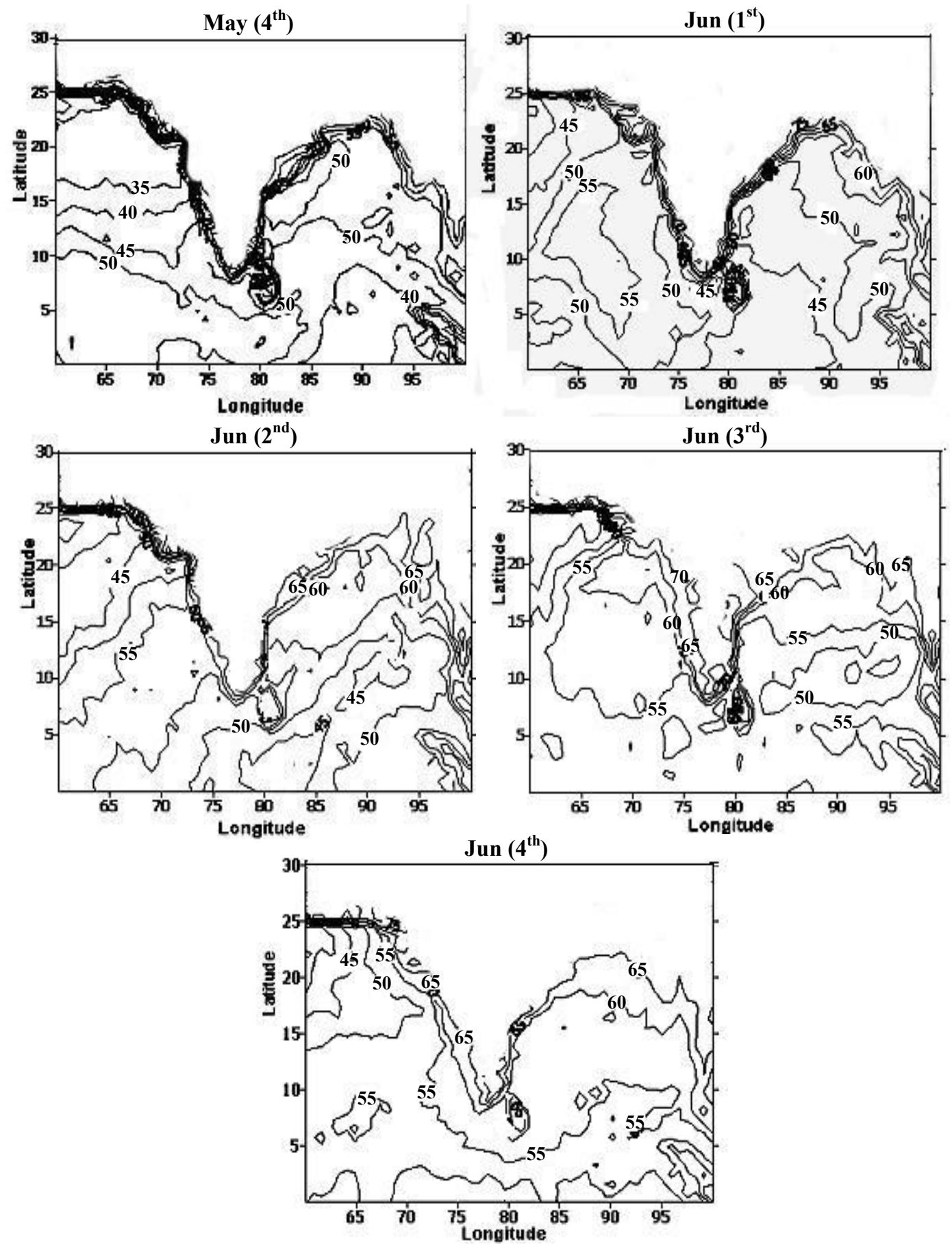

Fig. 1. Weekly variations of TPW $\left(\mathrm{kg} / \mathrm{m}^{2}\right)$ prior and after onset of monsoon during 1997 (June 2nd week figure corresponds to the monsoon onset week).

Table 1. Monsoon onset day during 1988 to 1998 (from Indian Meteorological Department, Pune).

\begin{tabular}{cccccccccccc}
\hline Year & 1988 & 1989 & 1990 & 1991 & 1992 & 1993 & 1994 & 1995 & 1996 & 1997 & 1998 \\
\hline Onset date of Monsoon & 26 May & 3 June & 19 May & 2 June & 5 June & 27 May & 28 May & 8 June & 3 June & 9 June & 2 June \\
\hline
\end{tabular}




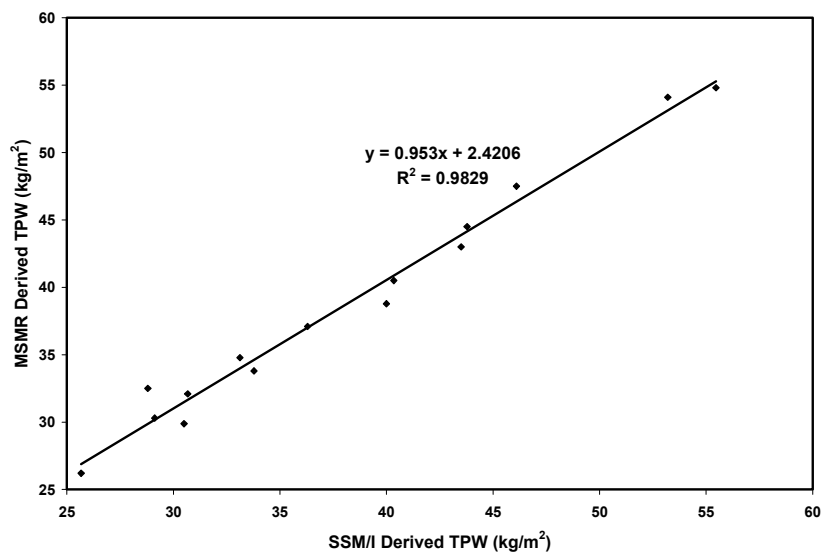

Fig. 2. Scatter Plot between SSMI derived TPW and MSMR derived TPW for June 2000.

Boulder, Colorado, USA. The weekly and monthly averaged TPW $\left(\mathrm{kg} / \mathrm{m}^{2}\right)$ over the Indian sub-continent have been calculated using the following algorithm (Alishouse et al., 1990):

$$
\begin{gathered}
\mathrm{TPW}=232.89-0.1486\left(\mathrm{~T}_{\mathrm{B} 19 \mathrm{~V}}\right)-0.3695\left(\mathrm{~T}_{\mathrm{B} 37 \mathrm{~V}}\right) \\
{\left[-1.8291-0.006193\left(\mathrm{~T}_{\mathrm{B} 22 \mathrm{~V}}\right)\right]\left(\mathrm{T}_{\mathrm{B} 22 \mathrm{~V}}\right),}
\end{gathered}
$$

where $T_{B 19 V}, T_{B 37 V}$ and $T_{B 22 V}$ are brightness temperatures at $19.35,37$ and $22.235 \mathrm{GHz}$ in vertical polarization, respectively.

The TPW retrieved from SSM/I has been compared with the TPW retrieved from IRS P4 multifrequency scanning microwave radiometer (MSMR) data of the same region using the algorithm given in Eq. (1). IRS P4 MSMR sensors onboard IRS-P4 (Oceansat - 1) which was launched by the Indian Space Research Organisation on 26 May 1998. The MSMR provided global microwave brightness temperature measurements at $6.6,10.65,18.0$ and $21.0 \mathrm{GHz}$ frequencies with vertical and horizontal polarizations. For TPW calculation using MSMR data, algorithm (Eq. 1) developed by Alishouse et al. (1990) was used with the brightness temperature 18 and $21 \mathrm{GHz}$ vertical polarization instead of 19 and $22 \mathrm{GHz}$.

\section{Results and discussion}

Using Eq. 1, weekly averaged TPW have been computed to examine the behavior of TPW in the week of the onset of monsoon at the Kerala coast. Weekly variations of TPW over the adjacent oceanic regions bounded by 60 to $100^{\circ} \mathrm{E}$ longitude and 0 to $25^{\circ} \mathrm{N}$ latitude have been analyzed two weeks prior and two weeks after the monsoon onset. The behavior of TPW for the onset week of monsoon and two weeks prior and after the onset week are found to be very similar, with little change between 1988-1998. In Fig. 1, an example of TPW behavior for two weeks prior and two weeks after the onset week of monsoon has been shown for the year 1997. The TPW over the Arabian Sea changes significantly
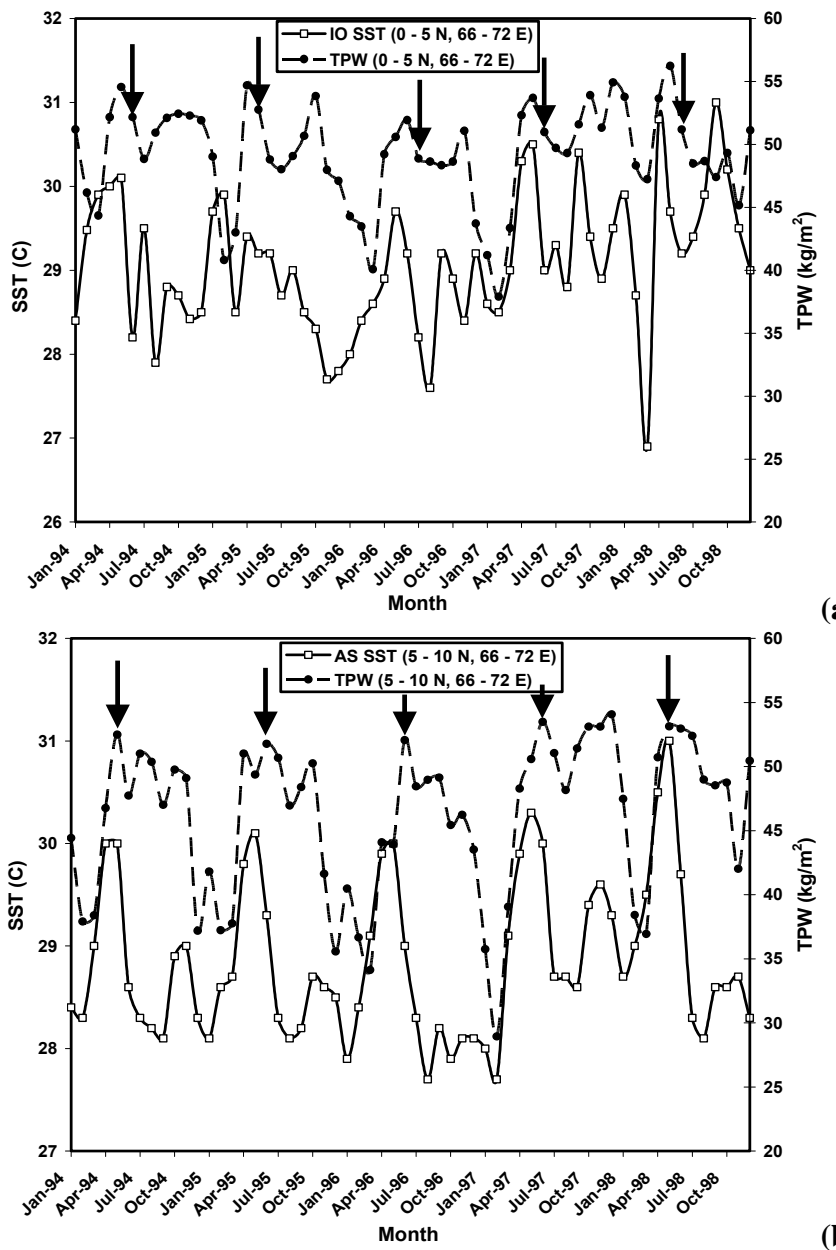

(a)

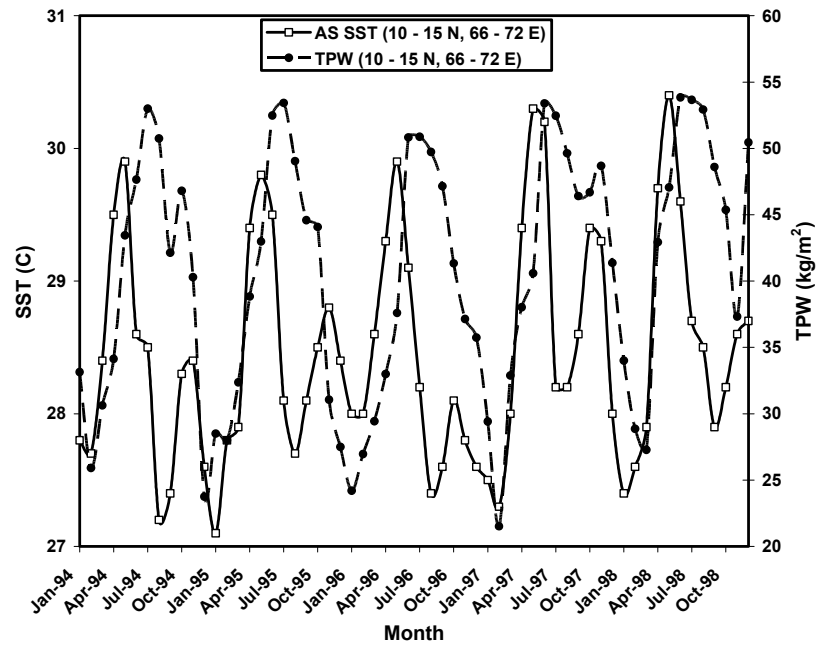

(c)

Fig. 3. Monthly variations of TPW with SST during 1994 to 1998 in (a) $0-50^{\circ} \mathrm{N}$, (b) $5-10^{\circ} \mathrm{N}$ and (c) $10-15^{\circ} \mathrm{N}$.

(see the contour values of TPW) before and after the monsoon onset. During the onset of monsoon in the year 1997 (2nd week of June, Table 1), the maximum TPW value of $55 \mathrm{~kg} / \mathrm{m}^{2}$ is found over the Arabian Sea coast. The maximum value of TPW persisted for about a week after the onset of monsoon in the second week, and afterwards the TPW 


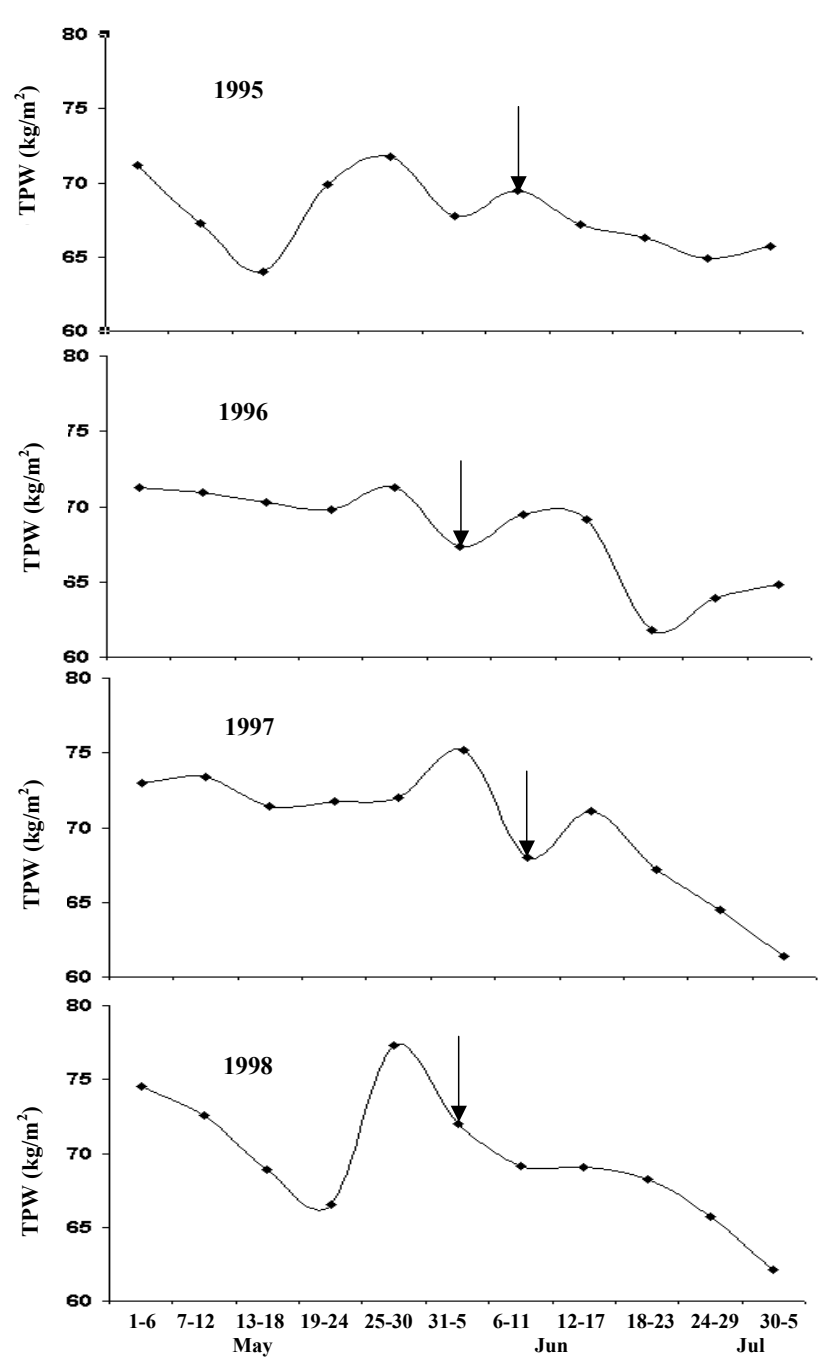

Fig. 4. Weekly variations of TPW in the latitude zone $10-15^{\circ} \mathrm{N}$ for 1995-1998.

value decreased during the 4th week. Such type of systematic behavior has been observed during 1988 to 1998, but the results are shown here for the year 1997 only. It is difficult to validate the TPW deduced from satellite data especially over the ocean, however, we have shown the correlation between TPW obtained from SSM/I and MSMR (IRS-P4 Oceansat) sensors. We have compared the TPW retrieved from SSM/I with the TPW retrieved from MSMR for the same region. Here, one may note that the SSM/I data was available in the grid resolution of $25 \mathrm{~km} \times 25 \mathrm{~km}$ and MSMR data was available in the grid of $50 \mathrm{~km} \times 50 \mathrm{~km}$, the brightness temperature data were extracted for same bounded region and averaged for the month of June 2000 for comparison. The comparison of TPW retrieved from SSM/I and MSMR (Fig. 2) shows a very high correlation $\left(R^{2}=0.98\right)$. The details of the comparison of SSM/I and MSMR data has also been discussed recently by Varma et al. (2002).

Figure 3 shows the variations of TPW and SST over the Indian Ocean and the Arabian Sea during 1994 to 1998 for $0-5^{\circ} \mathrm{N}$ (Fig. 3a), $5-10^{\circ} \mathrm{N}$ (Fig. 3b) and $10-15^{\circ} \mathrm{N}$ (Fig. 3c) latitude and $66-72^{\circ}$ longitude zones. The arrows show the onset month of the monsoon over the Kerala coast of India. For latitudinal zone $0-5^{\circ} \mathrm{N}$, no correlation of TPW and SST has been observed (Fig. 3a), whereas for other latitude zones, higher correlation of TPW and SST (of the Indian Ocean and the Arabian Sea) are clearly seen (Figs. $3 \mathrm{~b}$ and c). The maximum value of SST $\left(\sim 30^{\circ} \mathrm{C}\right.$ or more $)$ in the $5-15^{\circ} \mathrm{N}$ latitude zone is found one month prior to the maximum value of TPW or the onset of monsoon. The maxima of TPW shows a close relationship with the onset date of monsoon, which also has a close relationship with the SST of the Indian Ocean (IO_SST). The close correlation shows that the monitoring of SST may give early information about the onset of monsoon one month prior to the TPW. The trend of increase of TPW to maximum after an increase in IO_SST and SST of the Arabian Sea (AS_SST) in the $5-15^{\circ} \mathrm{N}$ latitude zone indicates the onset month of monsoon at the Kerala coast.

In order to examine a close relationship with TPW and the onset day of monsoon, six days averaged TPW have been computed. Due to poor daily temporal coverage, six days of averaged TPW has been considered for better accuracy and better temporal coverage, although the SSM/I sensor covers the whole globe in two days with few areas missing in data due to various limitations. Figure 4 shows the variations of six days of averaged TPW over the latitude region $10-15^{\circ} \mathrm{N}$ and longitude $66-72^{\circ} \mathrm{E}$ for the period $1995-1998$. In the latitude zone $10-15^{\circ}$, maximum TPW is seen $7-12$ days prior to the onset of monsoon. Maximum increase in TPW $\left(\sim 10 \mathrm{~kg} / \mathrm{m}^{2}\right)$ is seen in the year 1998 compared to a $3-5 \mathrm{~kg} / \mathrm{m}^{2}$ increase in the years 1995-1997 (Fig. 4), which may be attributed to the El-Nino effect. The TPW is seen to decrease during and after the week of the monsoon onset. We have also analyzed six days of averaged TPW for the 0 $5^{\circ} \mathrm{N}$ and $5-10^{\circ} \mathrm{N}$ latitude zones, but no significant relations of TPW with the monsoon onset were found.

\section{Conclusion}

The weekly and monthly variations of TPW over the Arabian Sea and the Indian Ocean are well correlated with onset day of monsoon over the Indian sub-continent. The maximum value of TPW in the $10-15^{\circ} \mathrm{N}$ latitude zone is seen to appear 7-12 days prior to the monsoon onset at the Kerala coast and so this zone is a key zone for Indian summer monsoon prediction. The analysis of monthly TPW and SST data in the $5-15^{\circ} \mathrm{N}$ latitude zone indicates the onset month of the monsoon. Further, the analysis of six days averaged data of TPW reveals close relation of TPW with monsoon onset only in the $10-15^{\circ} \mathrm{N}$ latitude zone. The present results suggest that the launch of microwave sensors with better spatial and temporal coverage may prove to be very useful useful to predict the onset of the Indian monsoon on the Kerala coast. 
Acknowledgements. The NOAA/NASA Pathfinder Programme EASE-Grid brightness temperature data were obtained from the National Snow and Ice Data Center, Boulder, Colorado, USA. We are grateful to M. Rajeevan, IMD, Pune for providing us monsoon onset date. The SST data were supplied by IMD, Pune. One of the authors (RPS) is grateful to Space Application Center, Ahmedabad for the availability of MSMR data through Announcement of Opportunity Program. We are grateful to the anonymous reviewer for his comments/suggestions which have helped us to improve the current version of the paper.

Topical Editor O. Boucher thanks a referee for her/his help in evaluating this paper.

\section{References}

Alishouse, J. C., Snyder, S. A., Jennifer, V., and Ferraro, R. R.: Determination of oceanic total precipitable water from the SSM/I, IEEE Transactions on Geoscience and Remote Sensing, 28, 811816, 1990.

Ferraro, R. R., Weng, F., Grody, N. C., and Basist, A.: An eightyear (1987-1994) time series of rainfall, clouds, water vapor, snow cover, and sea ice derived from SSM/I measurements, Bull. American Meteorological Society, 77, 891-905, 1996.

Hollinger, J.: DMSP SSM/I calibration/validation, Final Report, parts 1 and 2, Nav. Res. Lab., Washington, D.C., 1991.

McFarland, M. J., Miller, R. L., and Neale, C. M. U.: Land surface temperature derived from the SSM/I passive microwave brightness temperatures, IEEE Transactions on Geoscience and Remote Sensing, 28, 839-845, 1990.
Prabhakar, C., Chang, H. D., and Chang, A. T. C.: Remote Sensing of Precipitable Water over the Oceans from Nimbus 7 Microwave Measurements, J. Appl. Met., 21, 59-68, 1982.

Ross, R. J. and Elliott, W. P.: Tropospheric Water Vapor Climatology and Trends over North America: 1973-93, J. Climate, 9, 3561-3574, 1996.

Schluessel, P., and Emery, W. J.: Atmospheric water vapour over oceans from SSM/I measurements, Int. J. Remot., 11, 753, 1990.

Simon, B. and Joshi, P. C.: Determination of moisture changes prior to the onset of south-west monsoon over Kerala using NOAA TOVS satellite data, Meteorol. Atmos. Phys., 53, 223-231, 1994.

Simon, B., Joshi, P. C., Thapliyal, P. K., Pal, P. K., Sarkar, A., Bhatia, R. C., Jain, R. K., Singh, D., Mukherjee, S. K., and Gupta, H. V.: Monsoon onset-2000 monitored using multi-frequency microwave radiometer on-board Oceansat-1, Current Sci., 81, 647651, 2001.

Singh, R. P., Mishra, N. C., Verma, A., and Ramaprasad, J.: Total Precipitable Water over Arabian and Bay of Bengal using SSM/I Data, Int. J. Remot., 21, 2497-2503, 2000.

Stephens, G. L.: On the Relationship between Water Vapor over the Oceans and Sea Surface Temperature, J. Climate, 3, 634-645, 1990.

Varma, A. K., Goirala, R. M., Mathur, A. K., Gohil, B. S. and Agarwal, V. K.: Intercomparison of IRS-P4-MSMR derived geophysical products with DMSP-SSM/I and TRMM-TMI finished products, Proc. Indian Acad. Sci. (Earth Planet. Sci.), 111, 247-256, 2002.

Weng, F., and Grody, N. C.: Retrieval of cloud liquid water using the special sensor microwave imager (SSM/I), J. Geophys. Res., 99, 25 535-25 551, 1994. 